\title{
Enterprise Meta Modeling Methods - Combining a Stakeholder-Oriented and a Causality-Based Approach
}

\author{
Robert Lagerström ${ }^{1}$, Jan Saat ${ }^{2}$, Ulrik Franke ${ }^{1}$, Stephan Aier $^{2}$, and Mathias Ekstedt ${ }^{1}$ \\ ${ }^{1}$ Industrial Information and Control Systems, the Royal Institute of Technology, \\ Osquldas väg 12, 10044 Stockholm, Sweden \\ \{robertl, ulrikf, mathiase\} @ics.kth.se \\ ${ }^{2}$ Institute of Information Management, University of St Gallen, \\ Mueller-Friedberg-Strasse 8, 9000 St Gallen, Switzerland \\ \{jan.saat, stephan.aier\}@unisg.ch
}

\begin{abstract}
Meta models are the core of enterprise architecture, but still few methods are available for the creation of meta models tailored for specific purposes. This paper presents two approaches, one focusing on the stakeholders' information demand of enterprise architecture and the other driven by causal analysis of enterprise system properties. The two approaches are compared and a combined best-of-breed method is proposed. The combined method has merged the strengths of both approaches, thus combining the stakeholder concerns with causality-driven analysis. Practitioners will, when employing the proposed method, achieve a relevant meta model with strong, and goal-adapted, analytic capabilities.
\end{abstract}

Keywords: Meta modeling, Enterprise Architecture, stakeholder concerns, causal modeling.

\section{Introduction}

Meta models are at the core of enterprise architecture (EA) concepts. They describe the fundamental artifacts of business and IT as well as their interrelationships in a single aggregate organizational model [42]. Such high level models provide a common language and a clear view on the structure of and dependencies between relevant parts of the organization. Meta models serve three main purposes [23]:

1. Documentation of the enterprise architecture

2. Analysis of the enterprise architecture

3. Planning and design of the enterprise architecture.

These three purposes are in turn crucial to the success of management tasks such as product planning, business development, or business process consolidation [24].

However, devising a good meta model is not trivial. Obviously, it is important that the meta model is relevant in relation to the management tasks it should support. At the same time it is also of outmost importance that the meta model employed is kept minimal so that it can be used in practice where time and resources available to spend on enterprise architecture are limited. Occam's razor - the famous principle that 
entities must not be multiplied beyond necessity - is a rule of thumb very much valid in the context of meta modeling.

This paper presents two different meta modeling approaches, both based on the idea that minimal meta models are best obtained by maintaining a strict focus on goals when in the phase of meta model creation. However, the two methods differ in important respects, and a combined, best-of-breed, method is therefore proposed.

The first, stakeholder-oriented, approach to meta modeling starts with stakeholder concern elicitation and is strongly driven by practitioners. The resulting meta model seeks to satisfy the stakeholders information demands, each connected to distinct application scenarios. The second, causality-based, approach is based on causal modeling of goals sought. Starting from these goals, the resulting meta model provides a range of elements and attributes linked together by causality. The meta model thus supports the analysis necessary to achieve defined goals [16]. Compared to the stakeholder-oriented approach, focus is set on attributes with causal relations rather than on elements.

According to method engineering literature [4, 5], a method consists of design activities, design results, information models, techniques and roles. The proposed combined method focuses on the design activities, by introducing a meta modeling procedure. The method combines the strengths of its two constituent parts, addressing stakeholder concerns through causality driven analysis.

The remainder of this paper is structured as follows. Section 2 discusses related works, putting the present contribution in context. Section 3 describes the two parent methods in greater detail, and includes an analysis of their strengths and weaknesses. Section 4 outlines the combined method, including a concrete example of a possible application scenario. Section 5 discusses the result and concludes the paper.

\section{Related Work}

A number of EA initiatives have been proposed, e.g. The Open Group Architecture Framework (TOGAF) [39], the Zachman Framework [45], Enterprise Architecture Planning (EAP) [38], and the General Enterprise Reference Architecture and Methodology (GERAM) [14]. There are also numerous meta models proposed for EA modeling, e.g. the ones presented by O'Rourke [33], Lankhorst [27], Frank [8], and Niemann [31]. These works tend to focus on the differentiation of meta models in viewpoints, often referred to as architecture layers, as well as proposing notations (syntaxes) to display the model content of the different viewpoints. Neither the larger frameworks nor the meta model oriented initiatives typically contain methods for meta model design or adaptation to suit specific stakeholder concerns (except on a very general level). Only a few meta models detail whether and how they support decision making and goal oriented modeling. Even fewer specify how the meta models can support analysis of different scenario designs.

In contrast to the general and enterprise-wide modeling languages found within the discipline of EA, there exist a large number of languages that serve more specific purposes. Software and system architecture description languages, for instance, focus on internal structure and design of software systems. In addition to capturing the 
overall structure of systems, analysis capabilities are often available, such as deadlock and interoperability analyses in Wright [3], and availability, security, and timeliness analyses in the Architecture Analysis and Design Language (AADL) [35]. Other examples of modeling languages with very specific purposes are found, for instance, in software security engineering, where languages such as UMLsec [18], secure UML [29] and misuse cases [36] have been tailored specifically for security analysis (rather than depicting overall architectural design). These languages provide good support for detailed modeling of concerns. However, they lack holistic scope, which means that a subject such as security is only covered from a limited (typically technical) point of view. Furthermore, they also miss a large class of concerns such as business/IT alignment, system maintainability and flexibility that are highly relevant when considering an enterprise as a whole.

There is also a discussion of business architecture as a complementary concept to IT architecture. Although there are a few contributions dealing with the definition and implementation of business architecture as well as the corresponding models in general $[21,40]$ or in specific industries [12] there is no discussion of methods for meta model design we are aware of.

Looking even broader we quickly turn to adjacent areas. There is much written on the subject of knowledge elicitation [10], i.e. how to capture existing knowledge about phenomena in a systematic way. This field of research is associated with artificial intelligence [28], requirements elicitation [32], ontological engineering [6], and Bayesian networks $[19,20]$. Most of the methods within these research fields focus on conducting experiments or interviews. Most of the methods are customized for a specific purpose, and since none of the methods mentioned deal with meta modeling it is difficult to employ them as meta model design methods off-the-shelf.

More specifically, there are some initiatives focusing on meta model integration $[22,37]$. However, these methods do neither detail how to create a meta model or a meta model fragment nor what specific purpose they serve.

Recently it has been reported on how the $i^{*}$ framework $[13,43]$ could support goal oriented analysis and modeling into EA. In [44] it is demonstrated how business and IT related goals could be explicitly modeled using $\mathrm{i}^{*}$ when constructing an EA. $\mathrm{i}^{*}$ promotes a meta model including among other things goals (and so called soft goals) and their dependencies. Presently, is $i^{*}$ however not a method for developing meta models, it is rather a meta model for expressing goals. Consequently, it does not help the EA modeler with delimiting the meta models, instead it is an (important) extension of it.

To conclude, frameworks and formal notations for EA are available, most of them evolved from software engineering or business modeling to the EA context. However, general, notation independent, methods for meta modeling, that take business-oriented (and non functional) requirements and potential application scenarios into account are rare. None of the methods, frameworks, and notations examined results in meta models, covers the entire EA domain, and is purpose oriented in the sense that there should be an explicit relation to the purpose of the resulting meta model and support for describing the purpose. Furthermore, there is little support of causality formalization or attributes in the available methods for enterprise meta model creation. 


\section{Meta Modeling Approaches}

\subsection{Stakeholder-Oriented Approach}

Stakeholder-oriented meta model engineering was first introduced by [23]. The scope of the approach covers the architectural layers strategy, organization, alignment, software and data, and infrastructure as proposed in [2, 42]. Starting point for the meta model creation are the stakeholders and their information needs (concerns). A stakeholder in this case can be understood as a role within an organization that may benefit from the information provided by the enterprise architecture, and therefore by the entities of the meta model. A stakeholder has certain concerns that may be supported by application scenarios of the enterprise architecture. Application scenarios, such as compliance management, product planning, business continuity planning or technology risk management can be supported by architectural analysis, such as dependency analysis or coverage analysis. An extensive list of application scenarios and analysis types can be found in $[31,41]$. In order to address multiple stakeholders concerns and to support a variety of application scenarios the meta model must include all relevant entities and relations. Therefore the method proposes stakeholder interviews to gather information about concerns and application scenarios. In a next step, meta model fragments to cover the collected concerns are created.

Table 1. Engineering of Meta Model Fragments for Example Scenarios [23]

\begin{tabular}{|c|c|c|c|c|c|}
\hline Scenario & \multicolumn{2}{|c|}{ IT Consolidation } & Business IT Alignment & \multicolumn{2}{|c|}{$\begin{array}{l}\text { Compliance } \\
\text { (IT-Ownership) }\end{array}$} \\
\hline $\begin{array}{l}\text { Object } \\
\text { Purpose } \\
\text { Concern } \\
\text { Stakeholder } \\
\text { Design } \\
\text { Strategies }\end{array}$ & \multicolumn{2}{|c|}{$\begin{array}{l}\text { Processes, Applications } \\
\text { Analysis } \\
\text { Cost of application opera- } \\
\text { tions and maintenance } \\
\text { Application architect } \\
\text { Consolidation of applica- } \\
\text { tions that are in use for a } \\
\text { similar purposes }\end{array}$} & $\begin{array}{l}\text { Processes, Applications } \\
\text { Analysis } \\
\text { Providing adequate IT for } \\
\text { business processes } \\
\text { Process owner } \\
\text { Providing IT functionali- } \\
\text { ties for each process step / } \\
\text { Reduction of media breaks }\end{array}$ & \multicolumn{2}{|c|}{$\begin{array}{l}\text { IT-related artifacts } \\
\text { Documentation } \\
\text { Correct implementation of } \\
\text { ownership policies } \\
\text { IT audit } \\
\text { Assigning explicit owners } \\
\text { to applications and other } \\
\text { IT-related artifacts }\end{array}$} \\
\hline Questions & \multicolumn{2}{|c|}{$\begin{array}{l}\text { Which applications are } \\
\text { used in the individual } \\
\text { processes (sorted by orga- } \\
\text { nizational unit, product, } \\
\text { and distribution } \\
\text { channel)? } \\
\text { Which system software of } \\
\text { the same type is currently } \\
\text { in use? }\end{array}$} & $\begin{array}{l}\text { Which process activities } \\
\text { are not IT supported? } \\
\text { Which processes include } \\
\text { media breaks? } \\
\text { Which activities are } \\
\text { supported by multiple } \\
\text { applications? }\end{array}$ & \multicolumn{2}{|c|}{$\begin{array}{l}\text { Are there applications for } \\
\text { which no owners have } \\
\text { been defined? } \\
\text { Are there applications that } \\
\text { have not been audited for } \\
\text { more than two years? }\end{array}$} \\
\hline \multirow[t]{2}{*}{$\begin{array}{l}\text { Meta } \\
\text { Model } \\
\text { Fragment }\end{array}$} & Product & \begin{tabular}{|c|} 
Distribution \\
Channel \\
\end{tabular} & \multirow[t]{2}{*}{ specialization part of } & & Org. Unit \\
\hline & Application & $\begin{array}{l}\text { System } \\
\text { Software }\end{array}$ & & Application & Person \\
\hline
\end{tabular}


These fragments are set into relation in order to achieve consistency and to eliminate redundancies. Finally the model fragments are integrated to create one holistic meta model to cover all entities and relationships needed (Table 1).

The method presented has been used in several industry projects, which led to continuous improvements [24]. Since most organizations do not start enterprise architecture projects in green field environments, occasionally company specific meta models or parts of it already exist and need to be integrated in the process sketched above. In this case modeling of the meta model fragments does not start from scratch but existing parts are modified according to the results of stakeholder interviews. In other cases, companies opt for the adoption of reference models for parts of the meta model. To support this situation, a common level of abstraction has to be found in order to integrate self modeled fragments and reference model fragments. Therefore domains are used to group semantically related architectural entities and create comparability. Furthermore a quantitative indicator to determine the usefulness of a reference model fragment for a specific model is introduced. This indicator determines the modification efforts of a reference model necessary to fit the specific meta model of the organization.

Consequently, the method supports

1. the development of meta models starting from scratch with stakeholders' concerns,

2. meta modeling using legacy and reference models, and

3. the integration of fragments from steps 1 and 2 .

\subsection{Causality-Based Approach}

The main focus of the causality-based approach is on creating a meta model tailored to suit specific goals. These goals can be business oriented and "high-level", such as reduce IT costs or improve customer satisfaction as well as more technical and concrete, such as increase system availability or improve system documentation. In order to achieve the goal, the approach stipulates that the goal is decomposed into more tangible and clearly operationalized sub goals. The goal decomposition and operationalization is made by considering the causal dependencies of the goals upon components of enterprises, such as systems, processes, services, information, etc. as well as their inherent properties such as process cycle time or system cost. The method thus focuses heavily on causal relations between attributes of entities in enterprise meta models. Thus, a meta model will contain entities and entity relations as well as attributes and causal relations between these attributes [25].

The first step is the identification of enterprise goals. The second step is the detection of those enterprise constructs that influence these goals. The effort aims to understand which attributes causally influence the selected goals. In subsequent iterations, attributes causally affecting the attributes found in the second step are identified. This iterative process continues until all paths of attributes, and causal relations between them, have been broken down into attributes that are directly controllable for the decision maker (Fig. 1). For instance, it might be identified that the goal improve customer satisfaction is affected by customer support process efficiency and customer web portal usability. In the next iteration the customer web portal usability might be affected by the, for the IT decision maker, directly controllable attributes web interface standardization and ERP system interoperability. 


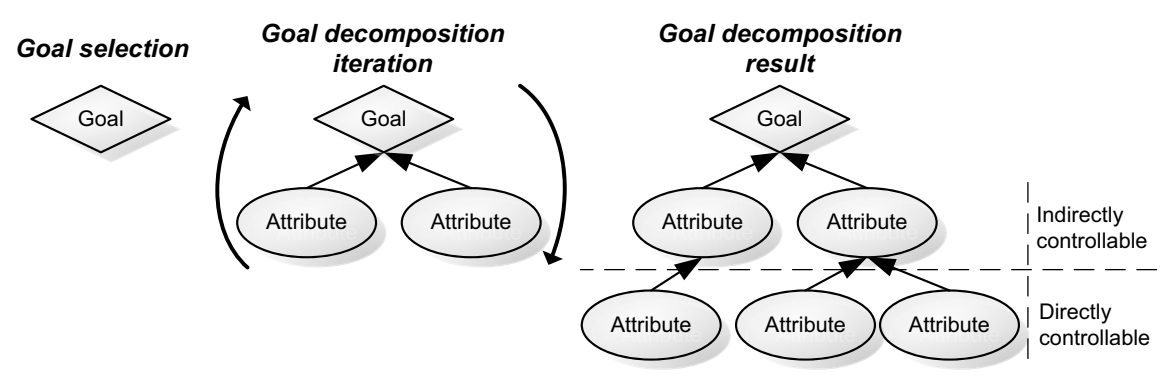

Fig. 1. Goal decomposition method

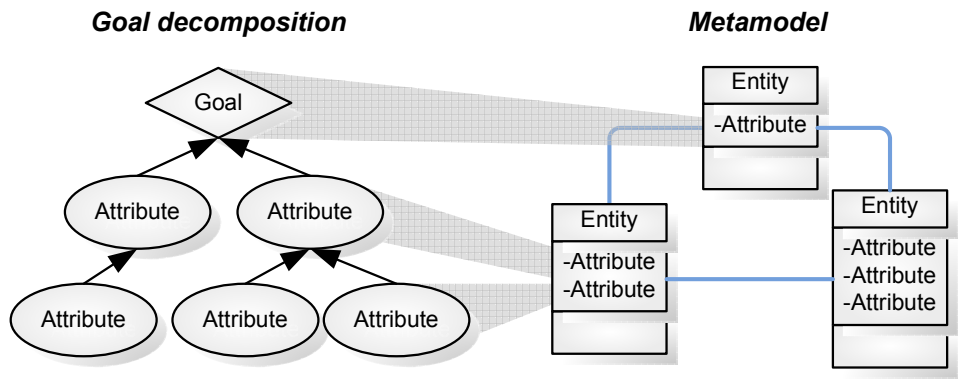

Fig. 2. Goal decomposition result and corresponding meta model

Once a complete set of attributes has been identified, it is time to decide upon enterprise constructs, i.e. meta model entities and relations (Fig. 2). These can either be physical artifacts, such as "computer" and "person", or more conceptual such as "data flow" and "process," depending on the goal decomposition. The previously introduced example uses the entity web interface with the attribute standardization as well as ERP system and interoperability. For more information see [11, 16, 26].

The goal decompositions can be visualized and formalized using various languages. By the criteria listed in [17], Extended Influence Diagrams (EIDs), an extension of Bayesian networks, is the preferred language. Employing the notation and mathematical foundation of EIDs provides the user with a language based on causality between a set of discrete variables. Using conditional probabilities and Bayes' rule, it is thus possible to infer the values of the variables in the goal decomposition under different architecture scenarios [15]. By using the EID formalism, the architecture analyses take the potential uncertainties of the knowledge of attribute values as well as the causalities as such.

\subsection{Comparison, Strengths and Weaknesses}

Both presented approaches propose processes to create meta models for organizations. Also, both approaches are independent of modeling notations. Yet there are differences in process, scope, focus and goals (Table 2). 
Table 2. Comparison of Stakeholder-Oriented and Causality-Based Approach

\begin{tabular}{|c|c|c|}
\hline Approach & Stakeholder-Oriented Approach & Causality-Based Approach \\
\hline Goal & $\begin{array}{l}\text { Support concrete application scenarios, } \\
\text { such as e.g. IT consolidation, product } \\
\text { planning, and post merger integration } \\
\text { in organizations based on stakeholders } \\
\text { concerns }\end{array}$ & $\begin{array}{l}\text { Support quality goals, such as e.g. business } \\
\text { value, IT governance maturity, and system } \\
\text { quality (e.g. maintainability, interoperabil- } \\
\text { ity, security, availability, performance) } \\
\text { by decomposing the goals into more con- } \\
\text { trollable metrics }\end{array}$ \\
\hline Focus & $\begin{array}{l}\text { Entities and relations } \\
-\quad \text { What does exist? } \\
-\quad \text { What entities are connected? }\end{array}$ & $\begin{array}{l}\text { Causal relations between attributes } \\
\text { - How are entities connected? } \\
\text { - What is the impact of a changing } \\
\text { entity/attribute on the entire architec- } \\
\text { ture? }\end{array}$ \\
\hline Scope & $\begin{array}{ll}- & \text { Entities } \\
- & \text { Entity relations }\end{array}$ & $\begin{array}{ll}- & \text { Entities } \\
- & \text { Entity relations with multiplicity } \\
- & \text { Attributes } \\
- & \text { Causal relationships between } \\
& \text { attributes }\end{array}$ \\
\hline $\begin{array}{l}\text { Meta } \\
\text { Modeling } \\
\text { Process }\end{array}$ & 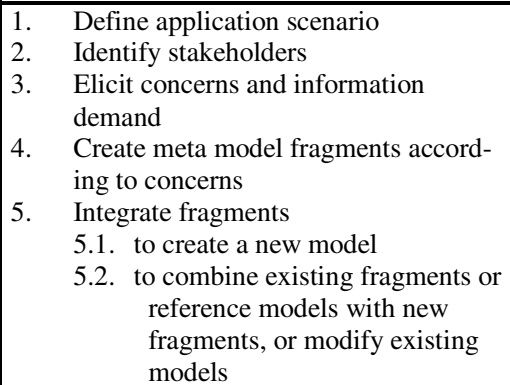 & 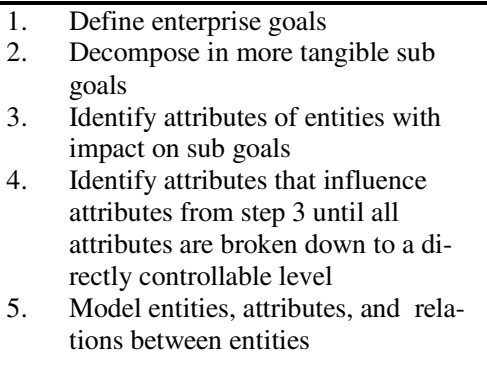 \\
\hline
\end{tabular}

Modeling goals can be diverse and complex, especially if main drivers such as different goals of an organization (causality-based approach) or different stakeholder concerns (stakeholder-oriented approach) cause conflicting modeling decisions. According to the main purposes of enterprise architecture, the meta model has to support documentation, analysis and planning. Both approaches focus on goal orientation and are generally suitable for these purposes. For that matter, the causality-based approach delivers measurable interconnections of entity attributes, which is especially important for analysis and planning capabilities. Stakeholder involvement ensures that there are specific roles with dedicated interest in their special application scenarios, which support the data gathering for the modeling process and also subsequent governance and maintenance aspects.

The focus and scope of the modeling approaches differ. The stakeholder-oriented approach focuses on entities and relations necessary to provide the groundwork for documentation, analysis and planning (What does exist? How are entities connected?). The causality-based approach takes a further step by not only including entities and relations, but focusing on attributes related to the entities and the causal relations between the attributes. This enhances the model, e.g. by using metrics and key performance indicators to evaluate and compare as-is situations and planning scenarios (How are entities connected? What are impacts of changes to one entity on 
the entire architecture?). Challenging prerequisite is however the existence of accurate data, as well as useful probabilities of occurrence for a certain situation. Not as a matter of meta modeling, but as an issue of operating the enterprise architecture, the cost of gathering and maintaining model information needs to be justified by benefits generated by it. Therefore the desired level of detail for entities and attribute information should be considered according to specific use cases and business needs [9, 30].

The modeling process of the causality-based approach is based on the idea to make strategic aspects measurable and controllable and create a meta model to consider these measures by the use of attributes. The method assumes that the meta model is built from scratch. The stakeholder-oriented approach is based on the information demand of interest groups and considers the scenario where organizations make use of legacy models and/or reference models in combination with new model fragments as well as creating the meta model on the green field.

\section{Method Construction}

\subsection{Goal, Scope, and Focus}

In order to create a best-of-breed method strengths of both approaches need to be combined. The resulting method needs a process oriented perspective to support concrete application scenarios and satisfy stakeholder needs as proposed by the stakeholder-oriented approach. At the same time, the metric oriented perspective from the causality-based approach is necessary to ensure sophisticated analysis of the meta model. This enhances the method with important capabilities, e.g. different versions of future scenarios can be compared to each other and evaluated based on the analysis and the impact local changes might cause in the entire enterprise architecture become visible. Thereby the scope of the meta modeling process involves entities, relationships, and attributes. The desired level of granularity results from the usefulness of the depth of information. This might be assessed by difference of the benefits generated from analysis information and the efforts of gathering and maintaining the data. Stakeholder involvement thereby ensures that there are concerns connected to model and analysis information, which is important for acceptance and maintenance matters.

\subsection{Method Description}

Combining the strengths of the two presented meta modeling methods a novel modeling process is proposed. Table 3 gives an overview on the eight-step procedure.

The method combines the stakeholder orientation with the causality-based approach. The following example illustrates the method using a sample application scenario.

\subsection{Example Scenario: IT Consolidation}

So far, the presented methods have only been evaluated in industry projects separately $[1,11,26,34]$. In this first joint proposal, we therefore use an example scenario to illustrate the method. The characteristics of this scenario will be outlined as we proceed through the process steps. 
Table 3. Meta Modeling Method Description

\begin{tabular}{l|l|l}
\hline Step No. & \multicolumn{1}{|c}{ Step } & \multicolumn{1}{c}{ Description } \\
\hline $1^{*}$ & Define application scenario & $\begin{array}{l}\text { Identification of concrete business situations, that enterprise } \\
\text { architecture shall support. }\end{array}$ \\
\hline $2^{*}$ & Identify stakeholders & $\begin{array}{l}\text { Identification of roles and persons that hold responsibility } \\
\text { for identified application scenarios. }\end{array}$ \\
\hline $3^{*}$ & $\begin{array}{l}\text { Elicit concerns and informa- } \\
\text { tion demand }\end{array}$ & $\begin{array}{l}\text { Investigation of what information stakeholders need in order } \\
\text { to fulfill their roles }\end{array}$ \\
\hline $4^{* * * *}$ & $\begin{array}{l}\text { Formalize information de- } \\
\text { mand into metrics }\end{array}$ & $\begin{array}{l}\text { Transform information demand and open questions into high } \\
\text { level goals and measures }\end{array}$ \\
\hline $5^{* *}$ & $\begin{array}{l}\text { Decompose in more tangible } \\
\text { sub goals }\end{array}$ & Break down high level measures in measurable goals \\
\hline $7 * * *$ & $\begin{array}{l}\text { Identify attributes of entities } \\
\text { with impact on sub goals }\end{array}$ & $\begin{array}{l}\text { Identification of model attributes that influence measurable } \\
\text { goals }\end{array}$ \\
\hline $8 *$ & Create meta model fragments & $\begin{array}{l}\text { Meta modeling including entities, relations and attributes } \\
\text { according to concerns and respective analysis metrics. } \\
\text { Identification of reusable fragments of existing meta models. }\end{array}$ \\
\hline Legend & $\begin{array}{l}\text { *based on stakeholder-oriented approach, **based on causality-based approach, ***based on } \\
\text { both approaches, ****new step }\end{array}$ \\
\hline
\end{tabular}

In the example case, the company is concerned with a lot of different processes, each supported by its very own IT systems. While the organization is still large, it has gone through considerable downsizing in recent years, and cost reduction is a priority throughout the whole enterprise. The CIO is faced with a decreasing budget, and has to cut costs while maintaining acceptable IT support to the core business.

1. Define application scenario. Faced with these circumstances, the CIO decides to make application consolidation a top priority. The CIO believes that there are numerous IT systems currently maintained that provide identical or similar functionality, which causes inefficiencies and high costs.

2. Identify stakeholders. To perform an application consolidation, the CIO needs to involve the system owners. These are top executives, each responsible for a certain business area, who also own the IT systems supporting their respective business. While the CIO has a responsibility to co-ordinate these systems, it is the business executives that formally own the systems and the personnel using them.

3. Elicit concerns and information demand. To make an informed decision on whether to phase out or keep any given system, the CIO needs to collect information on the characteristics of the system. This means that he must (i) get the consent of his peer executives, so that they will have the actual users collect the data, and (ii) decide on which criteria he is to use for the decisions.

4. Formalize information demand into quality goals. To structure his decision, the CIO seeks to make a cost-benefit analysis, with cost and benefits broken down as illustrated in Fig. 3. The need for the system in the organization is combined with the functional and non-functional qualities to define the benefits. The costs to keep the system, on one hand, and the costs to phase out the system, on the other hand, are combined to define the costs. 


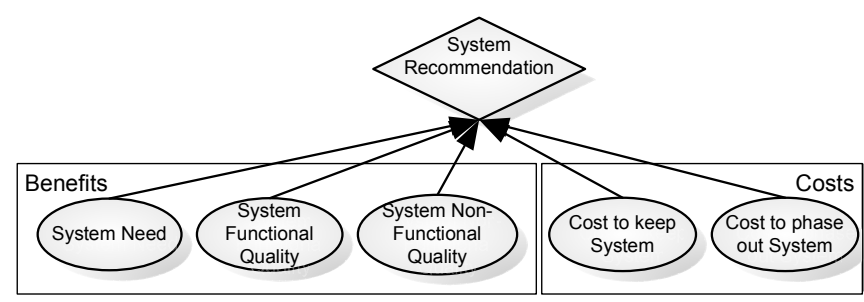

Fig. 3. Formalization of information demand

5. Decompose in more tangible sub goals. Clearly, the goals defined above need to be decomposed further. The need for the system can be measured by considering the criticality of the business processes supported by the system combined with an investigation of the redundancy, i.e. whether the processes are supported with the same functionality by several systems. Functional and non-functional qualities (availability, performance, interoperability, etc.) can be indicated by taking the ratio of the quality of service offered over quality that is required. The costs to keep the system can be estimated from current financial records, and those to phase it out depend on the modifiability and the level of coupling of the system at hand with other systems.

6. Identify attributes of entities with impact on sub goals. Following the decomposition above, some sample entities are System, Process, and Service. The system entity should have the attribute Recommendation, i.e. the top node illustrated above, but also functional and non-functional quality attributes such as Intrinsical availability (on an absolute scale) and Availability ratio (as compared to the requirements). These requirements, in turn, are attributes of the service offering support to the business process, and the process itself is attributed with, for instance, its Criticality. Needless to say, this is only a limited subset of all the attributes actually needed. Fig. 4. below gives a few more causal relationships in this limited example.

7. Create meta model fragments including entities, relations and attributes according to concerns and quality goals. The final meta model fragment in this example is illustrated below. The criticality of processes determines the criticality of the services supporting those processes. This is one input into the recommendation of whether to keep or phase out a system. Another input is the availability ratio of the system, as compared to the level of availability needed by the service.

8. Integrate fragments. The last step integrates the newly modeled meta model fragments with each other, respectively with already existing meta model fragments.

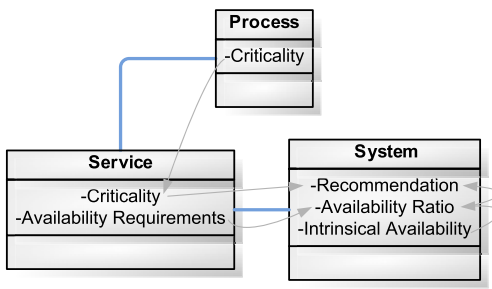

Fig. 4. Meta model fragment 


\section{Discussion and Conclusion}

In this paper we have analyzed existing approaches to EA meta model engineering. Based on this analysis we have proposed an integrated method to define situational EA meta models on a meta model element level as well as on a level of element attributes. Our basic assumption is, that EA models are no ends in themselves but have to provide a business value by supporting informed and well-founded decisions on how to continually transform the EA to fit an organization's goals.

Enterprise architecture data that does not contribute to such decisions should not be maintained in EA models since it often increases the EA maintenance efforts and thus reduces the acceptance of EA in an organization. Therefore our approach strictly derives relevant EA information from relevant application scenarios and stakeholder's concerns down to an attribute level.

Since this paper presents a first proposal of our enhanced method, the method has not yet been evaluated in a real case study. However, the partial evaluation of its components as well as the example given in section 4.3 may indicate the applicability of the method as well as the progressivity of the method compared with existing approaches.

Therefore our next steps will include the evaluation of the method in industry projects as well as the improvement of exiting EA maintenance approaches [e.g. 7] concerning the updates of EA element attributes. We will further investigate into the lifetime of accurate EA model information in order to further enhance EA application and maintenance processes.

\section{References}

1. Aier, S., Kurpjuweit, S., Schmitz, O., Schulz, J., Thomas, A., Winter, R.: An Engineering Approach to Enterprise Architecture Design and its Application at a Financial Service Provider. In: Proceedings of Modellierung betrieblicher Informationssysteme (MobIS 2008), Saarbrücken, GI/Köllen, pp. 115-130 (2008)

2. Aier, S., Winter, R.: Virtual Decoupling for IT/Business Alignment - Conceptual Foundations, Architecture Design and Implementation Example. Business \& Information Systems Engineering 51(2) (2009)

3. Allen, R.: A Formal Approach to Software Architecture Ph.D. Thesis, Carnegie Mellon University (1997)

4. Brinkkemper, S.: Method Engineering: Engineering of Information Systems Development Methods and Tools. Information and Software Technology 38(4), 275-280 (1996)

5. Brinkkemper, S.: Method-Engineering with Web-Enabled Methods. In: Brinkkemper, S., Lindencrona, E., Solvberg, A. (eds.) Informations Systems Engineering - State of the Art and Research Themes, pp. 123-133. Springer, London (2000)

6. Corcho, O., Gómez-Pérez, A., Fernández-López, M.: Ontological Engineering. Springer, London (2004)

7. Fischer, R., Aier, S., Winter, R.: A Federated Approach to Enterprise Architecture Model Maintenance. Enterprise Modelling and Information Systems Architectures 2(2), 14-22 (2007)

8. Frank, U.: Perspective Enterprise Modeling (MEMO) - Conceptual Framework and Modeling Languages. In: Proceedings of 35th Hawaii International Conference on System Sciences (2002) 
9. Franke, U., Johnson, P., Robert, L., Ullberg, J., David, H., Ekstedt, M., Johan, K.: A Method for Choosing Software Assessment Masures using Bayesian Networks and Diagnosis. In: Proceedings of 13th European Conference on Software Maintenance and Reengineering (2009)

10. Gaines, B., Shaw, M.: Using Knowledge Acquisition and Representation Tools to Support Scientific Communities. In: Proceedings of AAAI 1994, pp. 707-7141 (1994)

11. Gustafsson, P., Franke, U., Höök, D., Johnson, P.: Quantifying IT impacts on organizational structure and business value with Extended Influence Diagrams. In: Proceedings of First IFIP WG 8.1 Working Conference: The Practice of Enterprise Modeling (PoEM 2008), Stockholm, Sweden. LNBIP, vol. 15, pp. 138-152. Springer, Heidelberg (2008)

12. Huschens, J., Rumpold-Preining, M.: IBM Insurance Application Architecture (IAA) - An overview of the Insurance Business Architecture. In: Mertins Bernus, K., Schmidt, G. (eds.) Handbook on Architectures of Information Systems, vol. 2, pp. 669-692. Springer, Berlin (2006)

13. i*wiki: I-Star-Wiki (2009), http://istar.rwth-aachen.de (last access: 17.02.2009)

14. Ifip-Ifac: GERAM: Generalised Enterprise Reference Architecture and Methodology, Version 1.6.2, IFIP-IFAC Task Force (1998) (last access: 12.01.2005)

15. Jensen, F.: Bayesian Networks and Decision Graphs. Springer, Heidelberg (2001)

16. Johnson, P., Ekstedt, M.: Enterprise Architecture - Models and Analyses for Information Systems Decision Making. Studentlitteratur, Pozkal (2007)

17. Johnson, P., Lagerström, R., Närman, P., Simonsson, M.: Enterprise Architecture Analysis with Extended Influence Diagrams. Information Systems Frontiers 9(2) (2007)

18. Jürjens, J.: Secure Systems Development with UML. Springer, Heidelberg (2005)

19. Kadane, J., Wolfson, L.: Experiences in Elicitation. The Statistician 47(1) (1998)

20. Keeney, R., von Winterfeldt, D.: Eliciting Probabilities from Experts in Complex Technical Problems. IEEE Transactions on Engineering Management 38(3) (1991)

21. Kilov, H.: Business Models - A Guide for Business and IT. Prentice Hall PTR, Upper Saddle River (2002)

22. Kühn, H., Bayer, F., Jungringer, S., Karagiannis, D.: Enterprise Model Integration. In: Bauknecht, K., Tjoa, A.M., Quirchmayr, G. (eds.) EC-Web 2003. LNCS, vol. 2738, pp. 379-392. Springer, Heidelberg (2003)

23. Kurpjuweit, S., Winter, R.: Viewpoint-based Meta Model Engineering. In: Proceedings of Enterprise Modelling and Information Systems Architectures (EMISA 2007), Bonn, Gesellschaft für Informatik, Köllen, pp. 143-161 (2007)

24. Kurpjuweit, S., Winter, R.: Concern-oriented Business Architecture Engineering. In: Proceedings of 24th Annual ACM Symposium on Applied Computing (SAC), Honolulu, Hawaii (2009)

25. Lagerström, R.: Analyzing System Maintainability using Enterprise Architecture Models. Journal of Enterprise Architecture 3(4), 33-42 (2007)

26. Lagerström, R., Johnson, P.: Using Architectural Models to Predict the Maintainability of Enterprise Systems. In: Proceedings of 12th European Conference on Software Maintenance and Reengineering (CSMR 2008), Athens, Greece, pp. 248-252 (2008)

27. Lankhorst, M.: Enterprise Architecture at Work: Modelling, Communication and Analysis. Springer, Berlin (2005)

28. Liou, Y.: Knowledge acquisition: issues, techniques, and methodology. In: Proceedings of ACM SIGBDP Conference on Trends and Directions in Expert Systems (SIGBDP 1990), pp. 212-236. ACM Press, New York (1990) 
29. Lodderstedt, T., Basin, D., Doser, J.: SecureUML: A UML-Based Modeling Language for Model-Driven Security. In: Jézéquel, J.-M., Hussmann, H., Cook, S. (eds.) UML 2002. LNCS, vol. 2460, pp. 426-441. Springer, Heidelberg (2002)

30. Närman, P., Johnson, P., Robert, L., Franke, U., Ekstedt, M.: Data Collection Prioritization for Software Quality Analysis. In: Proceedings of Electronic Notes in Theoretical Computer Science (2008)

31. Niemann, K.D.: From Enterprise Architecture to IT Governance. Elements of Effective IT Management. Vieweg, Wiesbaden (2006)

32. Nuseibeh, B., Kramer, J., Finkelstein, A.: Expressing the relationship between multiple view in requirements specification. In: 15th Int. Conf. on Software Engineering (1993)

33. O'Rourke, C., Fishman, N., Selkow, W.: Enterprise Architecture - Using the Zachman Framework. Thomson Learning, Boston (2003)

34. Raderius, J., Per, N., Ekstedt, M.: Assessing System Availability Using an Enterprise Architecture Analysis Approach. In: Proceedings of 3rd Workshop on Trends in Enterprise Architecture Research (TEAR 2008), Sydney, Australia (2009)

35. SAE: Society of Automotive Engineers: Architecture Analysis and Design Language (AADL) standard, Carnegie Mellon University (2009)

36. Sindre, G., Opdahl, A.L.: Eliciting Security Requirements by Misuse Cases. In: Proceedings of TOOLS Pacific 2000, pp. 120-131. IEEE Press, Los Alamitos (2000)

37. Song, X.: A framework for understanding the integration of design methodologies. ACM SIGSOFT Software Engineering 20(1), 46-54 (1995)

38. Spewak, S.H., Hill, S.C.: Enterprise Architecture Planning - Developing a Blueprint for Data, Applications and Technology. John Wiley \& Sons, New York (1993)

39. The Open Group: The Open Group Architecture Framework TOGAF - 2007 Edition (Incorporating 8.1.1). Van Haren, Zaltbommel (2007)

40. Versteeg, G., Bouwman, H.: Business architecture: A new paradigm to relate business strategy to ICT. Information Systems Frontiers 8(2), 91-102 (2006)

41. Winter, R., Bucher, T., Fischer, R., Kurpjuweit, S.: Analysis and Application Scenarios of Enterprise Architecture - An Exploratory Study. Journal of Enterprise Architecture 3(3), 33-43 (2007)

42. Winter, R., Fischer, R.: Essential Layers, Artifacts, and Dependencies of Enterprise Architecture. Journal of Enterprise Architecture 3(2), 7-18 (2007)

43. Yu, E.: Modelling Strategic Relationships for Process Engineering, Dissertation, University of Toronto. Dept. of Computer Science (1995)

44. Yu, E., Strohmaier, M., Deng, X.: Exploring Intentional Modeling and Analysis for Enterprise Architecture. In: Proceedings of Workshop on Trends in Enterprise Architecture Research (TEAR 2006), Hong Kong (2006)

45. Zachman, J.A.: A Framework for Information Systems Architecture. IBM Systems Journal 26(3), 276-292 (1987) 